\title{
On the Irrelevance of Formal General Equilibrium Analysis
}

\author{
Dave Colander \\ Middlebury College, Middlebury, Vermont 05753, USA.
}

Eastern Economic Journal (2018) 44, 491-495. https://doi.org/10.1057/s41302-018-0108-7; published online 12 April 2018

For many economists, general equilibrium theory lies at the heart of modern economics. One of a graduate economics student's rites of passage is learning general equilibrium theory, and developing proofs relating to existence, uniqueness and the welfare implications of the analysis. Classes quickly move beyond such issues, but not before a sense of general equilibrium's fundamental importance has been instilled deep in most student's mind.

The perceived importance of general equilibrium theory to modern economics can be seen in Franklin Fisher's article "The stability of general equilibrium — what do we know and why is it important?" [Fisher 2011]. In it, he lists four issues in general competitive equilibrium theory: existence, uniqueness, optimality and stability, and argues that we know a good deal about the first three of these questions. Specifically, we know that "under general conditions, competitive general equilibria do exist; (2) these equilibria are globally unique, however, only in quite special cases; and (3) under very general circumstances, such equilibria are Pareto efficient." (Under somewhat less general circumstances, any Pareto efficient allocation can be decentralized as a competitive general equilibrium.)

He sees the third property — the welfare property — as the most significant, arguing that the welfare theorems of general equilibrium provide "rigorous justification for the view that free markets are desirable." He concludes that "It is not an overstatement to say that they are the underpinnings of Western capitalism." He writes: "So elegant and powerful are these results (g.e.'s exploration and proofs of existence, uniqueness, and optimality) that most economists base their conclusions upon them and work in an equilibrium framework - as they do in partial equilibrium analysis."

Fisher also discusses problems in the foundation that general equilibrium provides for Western capitalism. In his article, he points out that "the justification for using an equilibrium framework depends on the answer to the question of stability." He argues that without a proof of stability, the underpinnings of Western capitalism are lacking. $\mathrm{He}$ writes "But there is a deeper lesson here. In such a model, where agents act on perceived opportunities, there can be no hope of proving theorems of general stability without strong assumptions" (p. 42). He concludes "The search for stability at great levels of generality is probably a hopeless one" (p. 43).

Other critics of mainstream economics similarly build on findings in general equilibrium analysis as key to their critiques. For example, critics of mainstream 
macroeconomics often cite the Sonnenschein-Mantel-Debreu general equilibrium theorem as undermining mainstream macro theory. This theorem proves that in the aggregation from individual demand functions to an aggregate demand function, important properties of the individual demand function do not carry over to the aggregate. This means that there can be multiple equilibria, associating different aggregate demand curves with the same set of individual demand curves, making it impossible to move from a microfoundation model to a unique aggregate model.

\section{WHY GENERAL EQUILIBRIUM ANALYSIS IS IRRELEVANT FOR POLICY ANALYSIS}

General equilibrium theory is impressive, but, for an applied economist such as myself, general equilibrium proofs are largely irrelevant. They are wonderful exercises in logic, but they have little to do with the real world.

The complexity vision of the economy sees all aspects of the economy as continually evolving. The policy focus is on the actual economy, not a hypothetical one. The actual economy does not need a proof of existence; it can be assumed to exist with deeper questions of existence left to philosophers. Moreover, a proof related to a particular institutional structure is of little use, since the economy is assumed constantly evolving and adjusting on many levels. If the conditions for equilibrium, stability and optimality currently do not exist, forces are set in motion that change those conditions. If perfect competition is unstable, institutions will adjust into a system that is more stable. If fully rational individuals are incompatible with existence, the nature of rationality and tastes will evolve, so that it is. If the equilibrium in the economy is perceived by most agents in the model as horrendous, institutions will evolve as agents attempt to head toward a perceived better equilibrium.

Western capitalism does not depend on general equilibrium theory. It would still exist if the theory is or is not provable, or even if general equilibrium theory had never been developed. An applied economist's role is to understand that evolution and to make suggestions about how changing agent's actions might make it work a little better. In summary, when one envisions the economy as a complex evolving system, as I do, general equilibrium proofs just are not very important, because having a formal theory is not very important.

\section{FRIEDMAN'S VIEW OF GENERAL EQUILIBRIUM}

In his article, Fisher hinted that some economists discount the importance of general equilibrium proofs, noting that Milton Friedman had remarked to him long ago that "the study of the stability of general equilibrium is unimportant, first, because it is obvious that the economy is stable, and second, because if it isn't stable we are all wasting our time." Fisher disagrees with Friedman and argues that Friedman should have known better. Fisher writes "In the first place, it is not at all obvious that the actual economy is stable. ... Beyond this, however, is a subtler and possibly more important point. Whether or not the actual economy is stable, we largely lack a convincing theory of why that should be so. Lacking such a theory, we do not have an adequate theory of value, and there is therefore an important lacuna in the center of microeconomic theory."

What Fisher does not explain is why we need a formal theory of value. He simply assumes that we do. Applied policy economics can operate quite well without it, and in fact, by freeing up resources currently devoted to the study of theoretical esoteric mind games and changing economist's research to the study of creative policy alternatives, not 
having such a theory might lead to better policy. So, while I agree with Fisher that Friedman was wrong to say that the economy is obviously stable, I find Fisher's argument against Friedman unsatisfying.

The problem with Friedman's argument is that it was not strong enough. What Friedman should have argued was that it does not matter whether we can prove stability or not; what matters is whether we believe the economy we have is currently sufficiently stable so that stable models are useful in thinking about the economy. That is a question that formal general equilibrium theory cannot answer, which means that for the large majority of policy issues, the formal study of the theory of value is close to irrelevant to applied policy economics.

\section{THEORY AS A BLUEPRINT OR AS A GUIDE TO CREATIVE POLICY MAKING}

None of what I am saying holds that theory is totally unimportant for policy. Far from it. But its importance is indirect, not direct. Theory is not a blueprint for policy; rather it is a collection of deep insights into models that might be useful in creative thinking about policy. It is to be admired and used, but not necessarily to be taken too seriously as a guide for policy.

The differing roles can be seen by thinking about the well-known "economist searching for his keys under a streetlight" joke. The punch line to the joke is when someone asks the economist where he lost the keys; he responds that he lost them far from there over in a dark field. When asked why he is searching under the streetlight, he responds "This is where the light is."

Critics of economic theorists like to tell that joke to emphasize the foolishness of theorists. That is not the argument I am making. I am a supporter of theory. Formal theory is the search under the light; it cannot search anywhere else. That search makes sense as long as its goal is not finding the keys, but discovering the topography of the land. Formal theorists should work jointly with policy makers, but they should each be clear about the domain of their research. Policy makers are out there searching for the keys in the dark. Theorists are providing them with general guidance for their search.

Alfred Marshall, building on Mill's approach, is probably the most well-known advocate of this pragmatic approach to policy analysis that I am suggesting. He advocated using a partial equilibrium, or one-thing-at-a-time, methodological approach in which one developed a collection of heuristic policy models that highlighted certain relationships, keeping all other considerations in the back on one's mind. All these other considerations had to be added back before the heuristic policy model was applied to reality. General equilibrium considerations were one such "back of the mind" consideration. There were many others, such as endogeneity of tastes, importance of norms, and limited agent rationality. For Marshall, economic theory was not a blueprint for policy, but rather an engine of analysis - a tool to be used when useful, and to put aside when not.

Marshall fully understood the general equilibrium interconnections among markets and that his supply/demand partial equilibrium tool was highly limited. But he believed that those general equilibrium interconnections involved dynamic interactions that would undermine any simple specification of those interactions that could be captured in the mathematics of the time [Colander 1995]. For Marshall, whose primary interest was in economic policy, not scientific theory, formal general equilibrium theory was a "back of the mind" sub-issue to be explored by a small number of specialists; it was not a 
blueprint for policy, and thus, formal proofs of existence, uniqueness, optimality and stability were unimportant.

\section{THE COST OF FOCUSING TOO MUCH ON GENERAL EQUILIBRIUM THEORY}

The largest problem with the economics profession's focus on general equilibrium theory is the opportunity costs of that exploration. Important policy problems are not addressed. Consider Pareto optimality and the welfare theorems, which Fisher sees as the underpinnings of Western capitalism. In a world, such as ours, where property rights cannot be allocated effortlessly and costlessly, economist's welfare theorems have little policy relevance. Does a policy maker care whether any Pareto efficient allocation can be decentralized as a competitive general equilibrium? The chance of discovering a realworld Pareto optimal policy that can be shown to harm no one in some infinitesimal way is essentially nil.

By focusing their theoretical policy analysis on Pareto optimal policies, economists avoid coming to grips theoretically with the messy value judgments that must be made in the policy space, which means that their theoretical models provide little guidance on how to deal with the messy problems of actual policy that are designed to achieve both efficiency and fairness. In its almost exclusive focus on efficiency, modern economists have moved away from Classical economist's utilitarian moral philosophy that underlay Classical economist's support of markets. Classical economists supported markets because they worked reasonably well in the real world, not because of any deductive proof of the benefits of markets.

Because economists focus so much on general equilibrium, numerous promising policy approaches that could have been explored are not. Specifically, policy related to formation - the establishment of institutions, and the feedback effects of activity on tastes and norms - have been given short shrift. Consider just one example. Economists have a theory of optimal taxes, but do not have a theory of optimal property rights, even though the world works quite differently with different property rights.

John Stuart Mill saw policy as taking a quite different approach than it has taken. For him, economic policy would focus on getting property rights right, not on achieving efficiency. In fact, he saw getting property rights right as being key to his support of capitalism over socialism. He writes

The laws of property have never yet conformed to the principles on which the justification of private property rests. They have made property of things which never ought to be property, and absolute property where only a qualified property ought to exist. They have not held the balance fairly between human beings, but have heaped impediments upon some, to give advantage to others; they have purposely fostered inequalities, and prevented all from starting fair in the race. That all should indeed start on perfectly equal terms is inconsistent with any law of private property: but if as much pains as has been taken to aggravate the inequality of chances arising from the natural working of the principle, had been taken to temper that inequality by every means not subversive of the principle itself; if the tendency of legislation had been to favour the diffusion, instead of the concentration of wealth - to encourage the subdivision of the large masses, instead of striving to keep them together; the principle of individual property would have been found to have no necessary connexion with the physical and 
social evils which almost all Socialist writers assume to be inseparable from it [Mill 1848, p. 209].

Notice that Mill's defense of capitalism does not rest on any proof of general equilibrium theory, or on welfare theorems. Instead, it specifically bases its support for markets on an issue that general equilibrium theory avoids, getting the allocation of property rights right. Fairness, not efficiency, is the key policy focus for Mill.

\section{CONCLUSION}

In conclusion, formal general equilibrium analysis is largely irrelevant to policy. In fact, the general equilibrium approach has the analysis precisely backwards. There is no need to prove that a decentralized system can exist or is best. We have a partially decentralized system that has evolved into a mixed system in order to assure continued existence. The policy question involves that real-world mixed system. The relevant policy question involves the nature of, and how much, centralization, and non-market coordination is needed to make our evolving decentralized system work. Theoretically that is a question that cannot be answered generally. But, by blending an understanding of markets with a study of history and institutions, it is a question that economists can shed light on.

\section{NOTES}

1. This is not to say that general equilibrium theory has no relevance for policy. It can have significant longrun influence and might lead to insights about policy that otherwise would have been missed. My argument is just that it is not of central importance to policy analysis.

2. The view of the role of theory is not unique to me. It was John Stuart Mill's and Alfred Marshall's view as well. Mill saw theory as providing what he called half-truths; theory was no blueprint. For Mill, policy had to be based on a blend of normative judgments, sensibilities, and theoretical insights and should not be seen as science. Marshall built his approach to policy on Mill's approach.

3. Marshall was also careful to state that even the results of his policy models were not definitive guides for policy. Following Classical economist's methodology, he emphasized that economic analysis was just one input into policy analysis and that economic welfare was only one type of welfare.

\section{REFERENCES}

Colander, David. 1995. Marshallian general equilibrium analysis. Eastern Economic Journal, 21(3): 281-293. Fisher, Franklin. 2011. The stability of general equilibrium - what do we know and why is it important?, in General Equilibrium Analysis: A Century after Walras, edited by P. Bridel. London: Routledge.

Mill, John Stuart. 1848. Principles of Political Economy with Some Applications to Social Philosophy. London: Longmans. http://www.econlib.org/library/Mill/mlP14.html. 